\title{
A água e o junco nos jardins aquáticos antigos e contemporâneos ${ }^{(1)}$
}

\author{
MAÍRA ROESSING(2), CLÁUDIA PETRY(3)
}

\begin{abstract}
RESUMO
O presente trabalho é uma revisão sobre o uso da água e de plantas aquáticas nos principais jardins da humanidade, objetivandose explorar a existência e o uso do junco, espécie de plasticidade peculiar - herbácea cosmopolita de verticalidade sublime - e com potencialidade fitorremediadora. Sua ausência é constatada nos jardins funcionais simbólicos da antiguidade, até os jardins estéticos do renascimento. Atualmente, vem sendo usado em jardins evocativos da água ou naqueles com tendências ecológicas. Assim, seu uso pode simbolizar o anseio humano de retorno às origens de viver em um ambiente saudável e sustentável.

Palavras-chave: plantas aquáticas, Juncus effusus, áreas úmidas.
\end{abstract}

\section{ABSTRACT \\ The water and the soft rush in the ancient and contemporary aquatic gardens}

This work presents a review about the usage of water and aquatic plants important gardens, and it intends to explore the existence and the usage of the soft rush in these gardens. Its absence in the ancient symbolical functional gardens and in the Renascence aesthetic gardens is noted. Nowadays, it has being used in evocative water gardens or in gardens with ecological tendencies. This way, the soft rush usage, a species of peculiar plasticity - herbaceous cosmopolitan of sublime verticality - and with phytoremediation potential, can mean the human desire of returning to the origins of living in a healthy and sustainable environment.

Keywords: aquatic plants, Juncus effusus, wet areas.

\section{INTRODUÇÃO}

No paisagismo, a composição de superfícies d'água com plantas aquáticas gera mais um estilo de jardim, o aquático. Sendo a água um recurso natural, de valor inestimável para a humanidade, a maximização do seu aproveitamento permitiu a evolução de vários povos. A antiga visão de dominar o território, ampliando áreas de cultivo para a alimentação humana, foi a principal justificativa para drenar pântanos e zonas úmidas ao longo da história da humanidade (DUBOS, 1981).

O desenvolvimento de técnicas que permitiram o transporte e o armazenamento da água também ampliou a gama de possibilidades de uso e o domínio de uns povos sobre outros, como, por exemplo, a criação dos aquedutos pelos romanos, que lhes permitiu ampliar seu território na antiga Europa. Somente um manejo refinado da irrigação possibilitou a elaboração dos jardins suspensos da Babilônia, pelo rei Nabucodonosor II (605-562 a.C.), na antiga Mesopotâmia (VAN ZUYLEN, 1994).

As zonas úmidas causavam sensações de medo e adversidade nas pessoas, estigmatizadas como locais iso- lados e perigosos, por transmitirem doenças e causar afogamentos, permanecendo selvagens até meados do século 19, ou seja, não sendo considerados locais de cultivo. Com o advento dos pensamentos higienistas nessa época, várias zonas úmidas foram manejadas também em áreas urbanas, e, assim, criaram-se vários grandes parques urbanos. As plantas desses locais, grandes maciços com raízes profundas, também eram associadas às características do mal, como se trouxessem a essência ruim das entranhas da terra (DUMONT-FILLON, 2002).

No fim do século 20, apresentava-se a nova tendência de preservação dessas zonas úmidas, com toda a flora local, pois garantiam o equilíbrio hídrico e a estabilidade geológica das regiões as quais integravam (AB'SABER, 2001). A legislação vem buscando utilizar princípios de preservação da flora e da fauna locais. No Brasil, o Código Florestal (Lei 4775 de 1965) é um exemplo disso, bem como a recente lei das águas e de ocupação do solo. DUMONT-FILLON (2002), na França, estudando o caso do pântano Vernier, provou que as políticas públicas atuais estão contribuindo para modificar essa imagem pejorativa das áreas úmidas. Os moradores já se orgulham de habitar

\footnotetext{
(1) Recebido para publicação em 08/01/2008 e aceito em 28/04/2009.

(2) Engenheira Agrônoma, Mestre em Agronomia pela Universidade de Passo Fundo (UPF). ma.roessing@uol.com.br;

${ }^{(3)}$ Engenheira Agrônoma, Ph.D., Professora Titular de Paisagismo e Floricultura do Programa de Pós-Graduação em Agronomia (PPGAgro) da Faculdade de Agronomia e Medicina Veterinária (FAMV) da UPF, Caixa Postal 611, 99.001-970, Passo Fundo, RS, Brasil. petry@upf.br (autora correspondente)
} 
um lugar selvagem e, por isso, de grande atração turística. LE FLOCH \& EIZNER (1997) também constataram, na pesquisa social efetuada com a população ribeirinha ao pântano da Sensée, que essa paisagem funciona como um esquema de apreciação da natureza.

Nesta revisão bibliográfica, buscar-se-á tratar, resumidamente, a partir do histórico dos jardins aquáticos, como se deu o uso da água e de plantas aquáticas em jardins. E, dentre essas, se o junco se faz presente. Em seguida, um breve zoneamento das plantas no jardim aquático permitirá compreender o local mais apropriado para o junco nesse tipo de jardim. Por fim, serão apresentados a potencialidade ornamental de Juncus effusus e seu uso em paisagismo, demonstrando a tendência à valorização das zonas úmidas.

\subsection{Uso da água e de plantas aquáticas nos jardins: his- tórico dos jardins}

No mundo antigo, a água cumpria, ao mesmo tempo, função prática e simbólica. Uma vez controlada e canalizada, gerava vida e proporcionava prazer estético. Desviada dos rios Tigre, Eufrates e Nilo para distribuição e armazenamento, tornou possível a criação de jardins que, desde os tempos remotos, foram as primeiras representações dos desejos do homem de desfrutar um ambiente agradável e tranquilo. Esse lugar complementava sua casa ou palácio, como manifestação de êxito e grandeza, além de oferecer abundantes sombras, produzir flores e frutas, e representar um lugar de descanso para o duro trabalho da existência humana. A água foi o elemento que tornou possível a criação do jardim e, em suas várias manifestações, ao longo da história dos jardins, tem continuamente aportado vida e interesse (PLUMPTRE, 1993). Além de fundamental, a água é um dos elementos mais plásticos no jardim, embora procure sempre se estabilizar numa superfície plana (LIRA FILHO, 2002).

O ser humano vem utilizando água em seus jardins há muitos anos. No antigo Egito, Ramsés III (faraó entre aprox. 1194-1163 a.C.) já construía lagos para manter diferentes espécies aquáticas, como lírios, nenúfares, entre outras. Mas nessa época, os jardins eram funcionais e simbólicos. O papiro, por exemplo, era bastante usado como matéria-prima (VAN ZUYLEN, 1994). O essencial do jardim egípcio era o espelho d'água, quadrado ou em forma de $\mathrm{T}$, abastecido por canais que traziam água do Nilo (BAZIN, 1988) e ornamentado por lótus, ninféias, acorus e papiros (PAEZ DE LA CADENA, 1982).

$\mathrm{Na}$ Pérsia, a origem dos Paradeisos - locais fechados com irrigação onde tudo se cultivava - a última citação de um jardim típico é do século 4 a.C. O grande valor da água, para os persas, vinha com sua tradição em técnicas hidráulicas como o ganat, condutos subterrâneos que diminuíam a perda d'água por evaporação naqueles áridos ambientes (PAEZ DE LA CADENA, 1982). Os Paradeisos eram jardins com quadros regulares, provavelmente para responder a concepções rituais, intercalados de pavilhões para o repouso. Para os persas, uma cruz dividia o mundo em quatro partes (o fogo, o ar, a água e a terra) e, no centro, sempre existia uma fonte. Isto perdura no jardim, onde um rio sai do Éden para irrigar o jardim, ali se dividindo em quatro canais (VAN ZUYLEN, 1994). De 226 a 637 d.C, a Pérsia foi dominada pelos árabes e, durante a dinastia Sassânida, todos os canais de irrigação foram destruídos e, com isso, perdeu-se a história e o registro in loco dos jardins persas (BAZIN, 1988). Contudo, a distribuição regular dos canteiros desses jardins foi reproduzida no ocidente, e a mesma distribuição continua se repetindo no desenho geométrico dos tapetes persas.

$\mathrm{Na}$ Europa antiga, os romanos usufruíram todo o potencial da água, por meio do consumo de água de boa qualidade, do cultivo das plantas e na medicina. A aplicação da engenharia à construção de canais e aquedutos, termas, cascatas e espelhos d'água, em Villas e áreas urbanas, permitiu o longo período de dominação romana. $\mathrm{O}$ pátio, o pergolado e o uso da topiaria são exemplos clássicos do estilo romano. Os jardins romanos eram compostos pelas mesmas plantas que os jardins egípcios, apenas em menor proporção, pois a prioridade eram as espécies hortícolas funcionais e alimentícias (PAEZ DE LA CADENA, 1982). Portanto, o junco continuava ausente nesses jardins.

$\mathrm{Na}$ Idade Média, a água ficou limitada à fonte central nos jardins de claustro. Apenas a ninféia parece ter sido ali utilizada, sendo a prioridade o uso de plantas medicinais e plantas para consumo (PAEZ DE LA CADENA, 1982). Na Espanha, manteve-se a tradição árabe de situar uma fonte, canais ou tanques em pátios e jardins, pelo som, pelo efeito visual e para aumentar a umidade relativa do ar, sobretudo no ambiente seco da Andaluzia (COLBORN, 1998). PAEZ DE LA CADENA (1982) citou apenas uma planta de margem, o copo de leite (Zantedeschia aethiopica), nesses jardins hispano-árabes.

A água foi protagonista nos grandes jardins clássicos europeus, sem plantas aquáticas de ornamento. Nos jardins do renascimento italiano, além das fontes planas, ela aparecia em movimento nas escadarias e em chafarizes, aproveitando o desnível natural do terreno nas Villas, como a Villa d'Este. Atualmente, têm-se plantas espontâneas, forrando os três degraus da cascata na Villa d'Este. Nos jardins clássicos franceses, desenhados por Le Notre no século 17, foram construídos os monumentais espelhos d'água, com um eficiente sistema de canalização que permitia ativar fontes e chafarizes em períodos alternados. Isso para agradar ao rei Luis XIV, que adorava percorrer o jardim de Versailles, vendo os elementos arquitetônicos de ornamentação e os diferentes efeitos da água no canal, nos espelhos d'água, nas bacias, nas fontes e nos chafarizes, escutando o barulho da água em movimento. O rei até escreveu um manuscrito entre 1702 e 1704 sobre a "Maneira de mostrar os jardins de Versailles" (VAN ZUYLEN, 1994).

Nos jardins ingleses, desenhados por paisagistas do mesmo século (XVII), a água estava sutilmente nas grutas e refletia as almas nos espelhos d'água e nos grandes lagos. Ainda não era comum o uso de plantas aquáticas, embora, em algumas imagens, fossem encontrados nichos. No final do século 18, o pintor impressionista francês Claude Monet retratou, em inúmeras obras, as ninféias de seu jardim, o qual, de acordo com análises dessas obras, parecia ter inspiração oriental, mas com traços de jardins ingleses.

No jardim assimétrico oriental, constituído de pedras, 
areia, água, musgo, árvores e flores, um elemento pode simbolizar outro. A areia rastelada pode significar a superfície de água de um lago em um jardim mineral (seco ou karensansui). As pedras, extremamente simbólicas e individualizadas pelos orientais, podem também, no Budismo zen, representar água ou uma cascata (BAZIN, 1988). O lago ou espelho d'água é fundamental no jardim oriental, pois acrescenta o yin, um dos dois componentes da natureza. E, quando é cercado por caminhos de pedras irregulares, transforma-se num caminho iniciático aos seus transeuntes. Para o oriental, a água encarna a variabilidade das cercanias do homem e é motivo de meditação; é indomável, podendo ser lúdica ou mortífera. Enfim, representa contrastes entre o simbólico e a abstração (PAEZ DE LA CADENA, 1982). O tratamento oriental do espaço é representado pelo uso magnífico da escala, que carrega, ao mesmo tempo, o sentido e o símbolo, sendo o bonsai o exemplo mais óbvio. Pequenas fontes podem representar grandes lagos.

Em relação aos jardins americanos pré-colombianos, testemunhos atestam que os Astecas construíam balsas em torno da capital Tenochtitlan, situada numa laguna pantanosa, onde a vida devia se desenvolver de forma auto-suficiente (PAEZ DE LA CADENA, 1982). Essas chinampas eram construídas com raízes entrelaçadas de plantas aquáticas, lírios d'água e ramos em decomposição (PIGEAT, 1997), ancoradas com plantas de salso e tifas. Sobre elas, havia $1 \mathrm{~m}$ de terra, onde se cultivavam hortícolas em geral, e a irrigação acontecia por capilaridade. No Peru, os jardins eram nas cercanias dos palácios e já apresentavam os pátios indígenas, locais de encontro.

A partir de relatos do século 19, constatou-se que o junco foi utilizado na Mongólia, no lago Kutawal, no feitio de malhas, que, consolidadas, suportavam terra em parcelas com superfície de até $10 \mathrm{~m}$ X $3 \mathrm{~m}$. Juncos vivos serviam de proteção a essas estruturas (PIGEAT, 1997).

Segundo PAEZ DE LA CADENA (1982), a inspiração e motivação para a criação de jardins têm origem na ideia paradisíaca. A água, estando presente, provoca uma fascinação natural, inata no ser humano, pois é a origem da vida. A água é luz, e sua presença garante frescor, seu movimento adiciona som, sua visão produz calma. $\mathrm{O}$ poder de reflexo proporciona a sensação de amplitude e, além disso, o aparecimento de vários elementos da fauna e flora. Quando a água está presente em um jardim, além proporcionar maior interesse, dá outra dimensão ao ambiente. Cria uma atmosfera especial e constitui um elemento de atração de primeira ordem. Com a água, muitas outras atrações podem ser colocadas no jardim, como fontes, cascatas, jatos d'água, pontes e, principalmente, as plantas aquáticas, as quais necessitam de uma grande quantidade de água em torno das raízes para sobreviver (GLÉMAS, 2000).

$\mathrm{O}$ vegetal, hoje, pode ter funções de vedete no jardim, com efeito pitoresco, como escultura, ou com poder evocativo simbólico e criador de ambiências, mas é, sobretudo, fonte de bem-estar (ESSE, 2005), sobretudo quando utilizado em horticultura terapêutica. Além disso, as plantas têm grande importância num jardim aquático, visto que proporcionam o realce e o efeito final característico do jardim. A água refletirá as cores, as formas e o porte das plantas utilizadas. (SWINDELLS, 1994). Se essas plantas não apresentarem efeitos plásticos ornamentais interessantes em alguns desses três quesitos, seja por meio das flores ou, principalmente, da folhagem, o jardim perde muito de seu aspecto vital. Por isso, deve-se determinar o local mais adequado para cada planta.

\subsection{Zoneamento das plantas no jardim aquático}

As plantas aquáticas são também chamadas de macrófitas aquáticas. Esse termo foi mencionado pela primeira vez por WEAVER \& CLEMENTS (1938), que as definiram como plantas herbáceas que crescem na água, em solos cobertos ou saturados com água. SCULTHORPE (1967) denominou macrófitas as hidrófitas vasculares. Contudo, esse termo excluiu as algas macroscópicas e as briófitas. Para o Programa Internacional de Biologia (IBP), macrófita aquática é a denominação mais adequada para caracterizar vegetais que habitam desde brejos até ambientes verdadeiramente aquáticos. Dessa forma, o termo inclui vegetais, desde algas macroscópicas até plantas vasculares.

A distribuição das plantas no ambiente aquático é variável e, dependendo do grau de adaptação da espécie, pode estar a variadas distâncias da superfície da água (Figura 1). Diversos autores classificaram as plantas aquáticas quanto a sua forma de vida ou hábito. De acordo com a classificação de IRGANG et al. (1984), podem ser classificadas em: flutuantes livres e fixas, submersas livres e fixas, emergentes, anfíbias e epífitas.

Esses grupos ecológicos são distribuídos paralelamente à margem dos cursos d'água, de maneira organizada, da margem para o interior da água, iniciando-se pelas plantas emersas, passando pelas plantas de folhas flutuantes, até as submersas fixas. No entanto, a turbidez da água, o vento e as partículas em suspensão podem influenciar essa distribuição, podendo haver plantas submersas livres e flutuantes fixas crescendo entre as emergentes (SCREMIN-DIAS, 1999).

Em geral, as plantas aquáticas são propagadas por sementes, por estacas ou por divisão de touceiras. A divisão de touceira é aplicada para a maioria das plantas aquáticas rizomatosas, quando essas apresentam entrenós encurtados (SWINDELLS, 1994).

Os vegetais terrestres, na natureza, estão organizados de maneira que todos vivam em equilíbrio e harmonia, em camadas: superior, arbustiva e forração. Da mesma forma, os vegetais aquáticos são organizados de modo a equilibrar o sistema. Um jardim aquático, para ser completo e equilibrado, deve imitar essa estrutura natural. Para tanto, a presença de certos vegetais é imprescindível. Nesse caso, em vez da classificação de IRGANG et al. (1984), de cunho ecológico para habitats, torna-se interessante simplificar a classificação, para uso funcional em jardins. GLÉMAS (2002) sugeriu dividir as plantas do jardim aquático em plantas oxigenantes, flutuantes, de margem, de borda, ou de ambiente hidromórfico.

A criação de zonas úmidas, com plantas aquáticas e de ambiente hidromórfico, recria um meio natural que permite aproveitar plenamente o mundo aquático, no qual, inclusive o aparecimento da fauna é mais intenso. PALAZZO JR. 
\& BOTH (2003) sugeriram, para atrair a avifauna, além da água em movimento, manter as bordas externas do lago no mesmo nível do solo, cobertas com grama, deixando partes mais rasas nas laterais internas do lago. Com certeza, além das aves e peixes, rãs e insetos podem ser atraídos rapidamente para esse ecossistema no jardim.

Para garantir a inércia térmica do lago, quando submetido a variações bruscas de temperatura, GLÉMAS (2002) sugeriu profundidades entre 60 e $80 \mathrm{~cm}$ e escolher locais que recebam 6 horas de exposição solar diárias. Convém ressaltar que essas profundidades não são adequadas em ambientes freqüentados por crianças pequenas sem acompanhantes.

A seguir, são comentadas os tipos de plantas dos jardins aquáticos, segundo GLÉMAS (2002).

\subsubsection{Plantas oxigenantes}

Invisíveis ou quase, essas plantas são indispensáveis. Como todas as plantas, elas produzem oxigênio graças à fotossíntese. Contudo, por viverem na água, o oxigênio será dissolvido nesse meio. Essa oxigenação natural facilita a vida da fauna aquática. Além disso, também utilizam uma parte dos nitratos resultante da matéria orgânica em suspensão na água, (IRGANG et al., 1984), participando ativamente da conservação e do bom equilíbrio. E, qualquer que seja a espécie, o crescimento das plantas submersas é muito rápido. Com isso, desde o primeiro ano de implantação, há a iminência de tornarem-se invasoras. Portanto, o manejo busca manter o equilíbrio dessa população. Se não houver plantas oxigenantes em boa quantidade, a taxa de oxigênio dissolvido na água não é suficiente. Observa-se que esse déficit favorece o desenvolvimento de algas, o que torna a água verde. No entanto, excesso de oxigênio compromete o desenvolvimento de outras plantas e, além disso, por falta de espaço, elas acabam desaparecendo do lago.

As plantas submersas possuem outras funções. Constituem um refúgio e suporte para os ovos dos peixes, que, protegidos, têm mais chances de eclodir e dar origem aos alevinos. Presas fáceis dos peixes maiores e dos próprios pais, para eles, essas plantas se tornam o lugar ideal, enquanto aqueles não possuem porte suficiente para defender-se. Também servem de alimento para a fauna aquática - peixes, pássaros e invertebrados, e o uso de duas ou três espécies pode valorizar mais a folhagem, evitando a invasão do lago por uma única espécie. Alguns exemplos de plantas oxigenantes são Elodea canadensis, Hippuris vulgaris, Myriophyllum sp., Potamogeton natans e Ranunculus aquatilis (GLÉMAS, 2002).

\subsubsection{Plantas flutuantes}

Colocadas na superfície da água, essas plantas deslizam de acordo com vento. Aparentemente inúteis, desempenham papel importante na depuração biológica do lago pelo fato de suas raízes retirarem os nitratos dissolvidos na água, e também, nos longos dias de verão, sua folhagem filtrar os raios solares, evitando que a água se aqueça demais e algas verdes se desenvolvam ali.

Além do papel funcional, certas espécies são interessantes pelo efeito estético, distinguindo-se pela cor da folhagem e beleza das flores. Entretanto, como muitas plantas aquáticas, podem se tornar invasoras, o que torna imprescindível o controle da população a fim de se evitar que se multipliquem, como o exemplo brasileiro que se tem do aguapé.

Para a implantação de plantas flutuantes, inserem-se algumas mudas na superfície da água, e elas se desenvolvem e multiplicam facilmente. Entretanto, há algumas espécies que não suportam invernos rigorosos e, nesse caso, recoloca-se a espécie no ano seguinte, ou conservam-se algumas mudas em um aquário cheio de água, protegido em ambiente interno, sob temperatura média de $15^{\circ} \mathrm{C}$. Algumas espécies conhecidas são Eichhornia crassipes, Pistia stratiotes, Stratiotes aloides e Trapa natans (GLÉMAS, 2002).

\subsubsection{Plantas de margem}

Com as raízes no solo inundado e a parte aérea exposta, as plantas de margem, também denominadas plantas de pântano, asseguram a transição entre a água e a borda do lago, sendo indispensáveis para dar vida e estética ao lago. Com a seleção e o plantio cuidadoso das espécies, descobre-se a harmonia e a beleza do jardim aquático. Essas plantas preferem zonas pouco profundas, mas sempre recobertas com água, entre 0 e $30 \mathrm{~cm}$ de profundidade (GLÉMAS, 2002). Essa plataforma pode ser protegida por uma mureta, a fim de se evitar a erosão. Mas há possibilidade de serem usadas plantas de margem no centro do tanque, desde que tenha sido prevista uma plataforma de plantio. A superfície do solo deve ser recoberta com água em 10 a $20 \mathrm{~cm}$ para estar sempre úmida. Outra técnica para disseminar essas plantas no lago consiste em cultivá-las em cestas, instaladas sobre suportes, como, por exemplo, blocos de pedra, sempre observando se o solo (ou substrato) está submerso. Acreditase que, em lagos naturais a implantação seja simples, pois basta colocar essas plantas no solo.

As plantas de margens são interessantes por suas raízes rasteiras, que têm papel preponderante na retenção do solo, limitando os fenômenos de erosão. A maioria dessas plantas é rústica e pouco exigente em manejo. Como todas as plantas aquáticas, são vigorosas e de rápido desenvolvimento, sobretudo quando a radiação solar aquece a atmosfera e a água na borda do tanque. Essa escolha possibilita um rápido resultado paisagístico, pois, algumas semanas após a implantação, um lago novo parece estar instalado há muito tempo.

Há bom número de espécies disponíveis para decorar as margens dos lagos de um jardim aquático, o que permite escolher as melhores para projetos personalizados. No Brasil, BAILONE (2007) sugere espécies tropicais, pois a disponibilidade de oferta no mercado da Floricultura é pequena. A insolação não representa problema às espécies de margem, mas elas também toleram meia-sombra. Para cada planta existe uma indicação das melhores associações, tanto no plano estético como no técnico. Algumas espécies utilizadas são: Acorus calamus, Calla palustris, Euphorbia palustris, Iris spp., Juncus spp., Butomus umbellatus, Lobelia spp., Lysichitum spp., Lysimachia spp., Typha spp., Mentha aquatica, Pontederia cordata, Equisetum spp. e Cyperus spp. (GLÉMAS, 2002; SWINDELLS, 1994). En- 
fim, o junco também encontra seu lugar no jardim aquático (figura 2).

\subsubsection{Plantas de borda ou de ambiente hidromórfico}

Entre o lago e o jardim, pode haver plantas que não necessitem de um meio permanentemente úmido. Essas ficam em áreas onde não haja camadas impermeáveis subterrâneas que retenham a água, mas, ainda assim, suportam inundações temporárias. Essas áreas devem ser regadas a intervalos regulares, como todo o jardim. É interessante trabalhá-las como maciços, para se ter maior impacto visual, o que também facilita a manutenção. As samambaias encontram aqui seu lugar de interesse no jardim aquático. Muitas preferem zonas úmidas, mas também se desenvolvem em lugar sombreado e rico em matéria orgânica. Outro clássico é o íris. Alguns vivem com as raízes submersas, enquanto outros auxiliam a manter a umidade no verão, mas não nos períodos frios, como é o caso das variedades de Iris kaempferi ou I. ensata. Essas variedades não toleram solos calcariados, com pH elevado (GLÉMAS, 2002). Exemplos de plantas de bordas: Agapanthus umbellatus ou A. africanus, Astilbe spp., Heracleum mantegazzianum, Darmera peltata, Hosta spp., Carex spp., Miscanthus spp., Osmunda regalis e Primula spp. (GLÉMAS, 2002). SWINDELLS (1994) citou ainda, para este grupo, Hemerocallis híbridos, Iris kaempferi e I. sibirica, Lobelia fulgens, Primula sp., Rheum palmatum e a espécie sul-brasileira, Gunnera manicata, ressaltando que necessitaria do maior espaço no jardim, entre todas as anteriores citadas, sugerindo uma área circular de $2 \mathrm{~m}$ a 2,5 $\mathrm{m}$ de raio.

GARBE (2001) sugeriu outras plantas para os jardins aquáticos atuais, além das tradicionais já citadas. Altas e com folhas lanceoladas, seriam Scirpus sp. e Stratiotes aloides, ou apresentando folhagem vermelha, Miscanthus sinensis 'silberfeder'. As floríferas seriam Lythrium salicaria e o junco florido, Butomus umbellatus (flor rosa); Alisma plantago-aquatica e Darmera peltata (flor branca); e Lysichiton americanus e Caltha palustris (flor amarela).

\subsection{Potencialidade ornamental de Juncus effusus e seu uso em paisagismo}

Os juncos são propagados por divisão de touceiras, pois são plantas rizomatosas que apresentam entrenós curtos em seus rizomas (figura 2B). O procedimento de divisão é o mesmo para outras tantas plantas aquáticas (canas, lírios e tifa) e herbáceas perenes ordinárias. Pela experiência prática com o junco, observa-se que a planta matriz deve ser retirada com cuidado do solo, dividindo com garfo a touceira a partir do seu interior, separando em partes menores que contenham parte aérea, rizomas e algumas raízes adventícias. As mudas devem ser selecionadas entre os talos jovens mais saudáveis e externos (SWINDELLS, 1994), pois o centro da touceira abriga a parte velha da planta.

Os juncos, Juncus spp., encaixam-se perfeitamente nas condições das margens de lagos. Vivazes e rústicos, suas hastes possuem cor verde brilhante. Esse brilho é favorecido, ao receber luz, como a do sol ou da lua, pelo seu formato cilíndrico (figura 2C). Suas inflorescências escuras, apesar do pouco valor ornamental, adicionam graça, sendo um elemento decorativo a mais na primavera e no verão. $\mathrm{O}$ cultivo pode ser a pleno sol ou a meia-sombra, dependendo da espécie ou da situação do jardim. Para que sua aparência fique mais densa e agradável, é indicado que seja plantado com espaçamentos maiores. A plasticidade envolve forma, cor e textura, e o junco tem forma delicada vertical (que denota ascensão), cor verde-escura brilhante e textura lisa e refinada, segundo LIRA FILHO (2002). Esse autor salienta que linhas verticais são nobres e inspiradoras, sobretudo no contraste com superfícies horizontais calmas do plano d'água; são vislumbradas como composições complementares, remetendo a estabilidade.

Observando-se a touceira de junco a partir de um eixo horizontal, têm-se a impressão que as hastes são tridimensionais nos diversos planos verticais, o que causa, em perspectiva, certa ilusão de ótica, como um 'efeito pisca-pisca', ou trompe l'oeil (técnica artística de enganar o olho) (figura 2C).

Certas variedades podem alcançar até $1,50 \mathrm{~m}$ de altura. Em ensaio realizado por ROESSING (2007), Juncus effusus desenvolvido em vaso de 5 litros, durante 240 dias, apresentou a maior haste, com altura de 1,11 m logo nos primeiros dias. Entretanto, esse cultivo em vasos em ambiente aberto não favoreceu a obtenção de hastes mais longas, pois, ao longo do tempo, as alturas diminuíram e as pontas das hastes secaram.

Na natureza, ERVIN \& WETZEL (2002) verificaram que o junco, macrófita dominante, fez com que a diversidade em torno de suas touceiras fosse reduzida, sobretudo pelo efeito do sombreamento.

O conjunto de hastes eretas de Juncus effusus forma uma grande touceira ornamental para uso em paisagismo. Essa verticalidade exacerbada e exótica, atributo que poucas espécies herbáceas têm (cavalinha), também resgata a ideia de sublimidade. Além da beleza, o junco, por sua característica fitorremediadora, é ideal para utilização em paisagismo ambiental, pois, embeleza, e também retira metais tóxicos da água, responsáveis por contaminá-la. Portanto, conclui-se que pode ser usado também com propósito de purificação do esgoto doméstico.

BREDA \& CONTE (2001) sugeriram uma estação residencial de esgoto com três tanques de decantação, um com pedras, para filtragem, e, por fim, um quinto tanque, contendo substrato composto por casca de arroz, areia e plantas de junco ou taboa. Acredita-se que a água que sair do último tanque estará purificada.

Em 1997, dentre os 28 projetos de jardins do Festival Internacional de Chaumont-sur-Loire, na França, cuja temática era a água, apenas em um - «A fonte de pássaros » de D. Lewis, Besançon, França - o junco foi utilizado ( $J$. effusus spiralis e $J$. inflexus). Isso porque nesse evento de paisagismo, a ênfase, naquele ano, ainda era para as técnicas e símbolos culturais relacionados à água, embora o próprio Jean-Paul Pigeat ressaltasse a dificuldade de manter os jardins do festival, que necessitavam de $50 \mathrm{~m} 3$ de água por dia (PIGEAT, 1997).

No entanto, se, até o fim do século 20, o junco esteve ausente dos jardins, acredita-se que a escolha pelo seu uso nos dias de hoje denote um resgate ao senso ecológico, por 
ser espécie perene e rústica, com plasticidade peculiar e exótica, sempre valorizando a água no jardim.

Para BAZIN (1988), o jardim nasceu do deserto, pois, segundo ele, o beduíno sedento, após percorrer o vasto deserto, via no horizonte a miragem dos oásis, de lugares refrescantes e verdejantes; ele até escutava o barulho da água correndo. Essa doce metáfora justifica a importância da água nos jardins, mesmo nos lugares mais inóspitos. $\mathrm{O}$ mesmo autor sugeriu que, no Renascimento, os jardins deixaram de ser jardins, e foram transformados teatros, com uso bastante artístico.

Entretanto, houve uma mudança na função da água nos jardins, a qual, no início, era usada para estruturá-los. Hoje, seu uso está sendo retomado, não apenas pela estética, mas, principalmente, pela necessidade do ser humano de ser útil, pois é necessário haver vontade ecológica na execução de jardins aquáticos, que, por serem ecossistemas complexos, devem ser bem elaborados. Portanto, o uso desse tipo de jardim simboliza um retorno às origens, resgata essa ideia de paraíso, especialmente quando se utilizam plantas potencialmente fitorremediadoras, como o junco. PUIBOUBE (1981), em seu estudo sobre paisagens familiares francesas, observou o junco nas beiras de pequenos lagos, como componente das paisagens típicas d'Ile-de-France, em que o solo é pesado e argiloso.

Para BACKES (2006), o paisagismo ambiental prevê a sucessão ecológica com a tridimensionalidade de espaços e do tempo. As plantas crescem em extratos e velocidades diferentes. Aplicando princípios da permacultura, o paisagismo ambiental se amplia, pois esse é o sistema de existência do ser humano na Terra: usando a energia naturalmente em fluxo, relativamente inofensiva, alimentandose e utilizando recursos naturais abundantes, sem destruir a vida na Terra (MOLLISON, 1998). Como exemplo de paisagismo ambiental em que o genius loci é valorizado, no parque de Bercy, em Paris, lagos são alternados com espaços selvagens, relembrando os antigos pântanos da região, e intercalados com maciços de floríferas anuais, entre tantos outros ecossistemas ali estabelecidos.

Essa evolução do manejo de parques e jardins acontece em função dos usos. FAYOLLE (2000), ao relatar a intervenção em uma área com um campo de futebol, para se construir um parque de 10 ha., próximo a Paris, salientou a mudança do plano paisagístico após consulta à comunidade. A equipe de paisagistas concluiu, após entrevista a 530 vizinhos, que as quatro prioridades eram: água, verde, animais e, por último, convivência e intimidade. Apenas um entrevistado manifestou interesse pelo campo de futebol; os outros buscavam resgatar a natureza. Esta tendência de gestão diferenciada na Europa é uma forma nova de gerenciar os espaços verdes públicos, buscando aparências mais naturais e sustentáveis. Contudo, não se pode abandonar a manutenção desses espaços, nem esperar que os custos sejam reduzidos rapidamente; é preciso intervir o mais breve possível e explicar toda a intervenção. Esses quatro passos, segundo HADDAD (2005), são necessários para que essa nova forma de gerenciar espaços públicos seja colocada em prática.

Sociedades que ‘secam' suas áreas úmidas, para TER-
RASON (1991), secam também os olhos dos que querem chorar, por considerarem o choro uma ação degradante. Para essas sociedades, segundo esse autor, é-se superior quando se nega e se esconde o sentimento, ao mesmo tempo em que se racionaliza o território, com o avanço de patrolas. Então, respeitar áreas úmidas e instalar lagos são ações que transformam o local. Uma bordadura ao primeiro plano permite contemplar o conjunto do plano de água. Conforme a vegetação aquática vai ascendendo para o fundo do jardim, a perspectiva vai ficando mais acentuada. $\mathrm{O}$ lago deve integrar-se ao jardim, ou seja, deve encontrar naturalmente o seu lugar, derretendo-se no jardim ou na paisagem existente.

PAEZ DE LA CADENA (1982) diz que os jardins do presente e do futuro exigem o respeito à diversidade, ao passado, sempre que possível, o abandono do individualismo, com metas comunitárias. Além disso, nesses jardins, unem-se campos de trabalho diferentes, recuperam-se materiais genéticos autóctones, aproveitando-se melhor seus valores funcionais e artísticos. Enfim, a concepção do ecossistema do jardim deve compreender e respeitar características peculiares da cultura dos povos, mas também dos locais.

\section{CONSIDERAÇÕES FINAIS}

O junco esteve ausente nos jardins da Antiguidade e do Renascimento. Após esse período, seu uso foi funcional em áreas úmidas e alagadas. Seus atributos plásticos ornamentais são sua forma vertical delicada e marcante, cor verdeescura brilhante e textura lisa e refinada, excelente uso em touceiras em paisagismo e, individualmente, em arranjos florais. Ele começa a ser utilizado, atualmente, em jardins de cunho ecológico, por agregar valor de plasticidade ornamental peculiar, de sustentabilidade em fitorremediação e em paisagismo mais adequado ambientalmente.

\section{REFERÊNCIAS}

AB'SABER, A. O suporte ecogeológico das florestas beiradeiras (ciliares). In: RODRIGUES, R.R.; LEITAO FILHO, H.F (org.) Matas ciliares: conservação e recuperação. 2.ed. São Paulo: Edusp/Fapesp, 2001. p. 15-26.

BACKES, T. Jardins ecológicos. Natureza, São Paulo, v. 19, n. 9, p. 94-96, 2006.

BAILONE, A.L. A magia das águas e as ninfas que nela habitam... Revista Brasileira de Horticultura Ornamental, Campinas, v. 13, n. 1, p. 13-20, 2007.

BAZIN, G. Paradeisos ou l'art du jardin. Paris: Chênes, 1988. 264p.

BREDA, C.C.; CONTE, M.L. O destino do esgoto doméstico. Globo Rural, São Paulo, v. 16, n. 185, p. 25, 2001.

COLBORN, N. Grandes trucos para pequeños jardines. Barcelona: Gustavo Gili, 1998. 144p. 
DUBOS, R. Namorando a terra. São Paulo: EPU/Melhoramentos, 1981. 150p.

DUMONT-FILLON, N. Les politiques publiques de paysage et de patrimoine: um outil de gestion des territoires (Le cas du marais Vernier, Eure, et des couteaux de la Roche-Guyon, Val d'Oise). Paris, Versailles, 2002. 302f. Thèse (Docteur de l'ENGREF) - École Nationale du Génie Rural, des eaux et des forêts de Paris/École Nationale Superieure du Paysage de Versailles.

ERVIN, G.N.; WETZEL, R.G. Influence of a dominant macrophyte, Juncus effusus on wetland plant species richness, diversity and community composition. Oecologia, Berlin, n. 130, p. 626-636, 2002.

ESSE, O.L. Quel rôle pour le végétal? Jardins de France, Paris, n. 556, p. 14-19, 2005.

FAYOLLE, P. Parcs et jardins: nouvelles pratiques, nouveaux usages: quelle conception, quelle gestion? Lien Horticole, Pérols, v. 38, n. 247, p. 19-21, 2000.

GARBE, P. Un jardin aquatique. Jardins de France, Paris, n. 3, p. 18-23, 2001.

GLÉMAS, P. Le jardin prend l'eau. Jardins de France, Paris, n. 4, p. 16-21, 2000.

GLÉMAS, P. Jardins d'eau: le bassin, les berges, les plantes et les poissons. Paris : La Maison Rustique, 2002. 126p.

HADDAD, Y. Paysage: gestion differenciée, de la réflexion à l'action. Lien Horticole, Pérols, v. 13 n. 462, p. 10, 2005.

IRGANG, B. E.; PEDRALLI, G.; WAECHTER, J. L. Macrófitas aquáticas da estação ecológica do Taim, Rio Grande do Sul, Brasil. Roessleria, Porto Alegre, p. 396-404. 1984.

LE FLOCH, S.; EIZNER, N. Le peuplier et l'eau, ou l'une des figures de la nature populaire. Courier de l'environnement de l'INRA, Paris, n. 30, p. 19-28, 1997.

LIRA FILHO, J.A. de. Paisagismo: elementos de composição e estética. Viçosa: Aprenda Fácil, 2002. 194p. Il. (Col. Jardinagem paisagismo. Série Planejamento paisagístico, v.2)

MOLLISON, B. Introdução à permacultura. Brasília: MA/ SDR/PNFC, 1998. 204p.
PAEZ DE LA CADENA, F. Historia de los estilos en jardinería. Madrid: Istmo, 1982. 370p.

PALAZZO Jr., J.T.; BOTH, M.do C. A natureza no jardim: guia prático de jardinagem ecológica e recuperação de áreas degradadas. 3.ed. Porto Alegre: Sagra Luzzatto, 2003. 109p.

PIGEAT, J.P. Que d'eau! Que d'eau! L'eau dans les jardins du XXIe siècle. In. 6e. FESTIVAL INTERNATIONAL DES JARDINS DE CHAUMONT-SUR-LOIRE. Chaumont-sur-Loire: Conservatoire International des Parcs et Jardins et du Paysage, 1997. 95p.

PLUMPTRE, G. Juegos de agua: la presencia del agua en el jardín desde la antiguedad hasta nuestros dias. Barcelona: Editora Gustavo Gili, 1993. 208 p.

PUIBOUBE, D. Les paysages de vos maisons: conseils pour organiser, planter, mettre en valeur. Paris: Du Moniteur, 1981. 159p.

ROESSING, M. Produção, caracterização morfo-anatômica e ornamental, e uso do Juncus effusus L. em paisagismo. 2007. 114f. Dissertação (Mestrado em Agronomia) - Programa de Pos-graduação em Agronomia da Faculdade de Agronomia e Medicina Veterinária, Passo Fundo, 2007.

SCREMIM-DIAS, E. O retorno à origem aquática. In: SCREMIM-DIAS et al.(org.) Nos jardins submersos da Bodoquema. Campo Grande: UFMS, 1999. p. 25-41.

SCULTHORPE, C. D. The biology of aquatic vascular plants. New York: St. Martin's Press, 1967. 610p.

SWINDELLS, P. El jardin acuático. Barcelona: Blume, 1994. 48p.

TERRASON, F. La peur de la nature. Paris: Sang de la terre, 1991. 192p.

UNITED STATES DEPARTMENT OF AGRICULTURE - Natural resources Conservation Service. Disponível em: $<$ http://plants.usda.gov/java/profile? symbol=JUEF $>$. Acesso em: 15 jul. 2006.

VAN ZUYLEN, G. Tous les jardins du monde. Paris: Gallimard, 1994. 175p.

WEAVER, J. E.; CLEMENTS, F. F. Plant ecology. New York: Mc Graw Hill Book, 1938. 601p. 


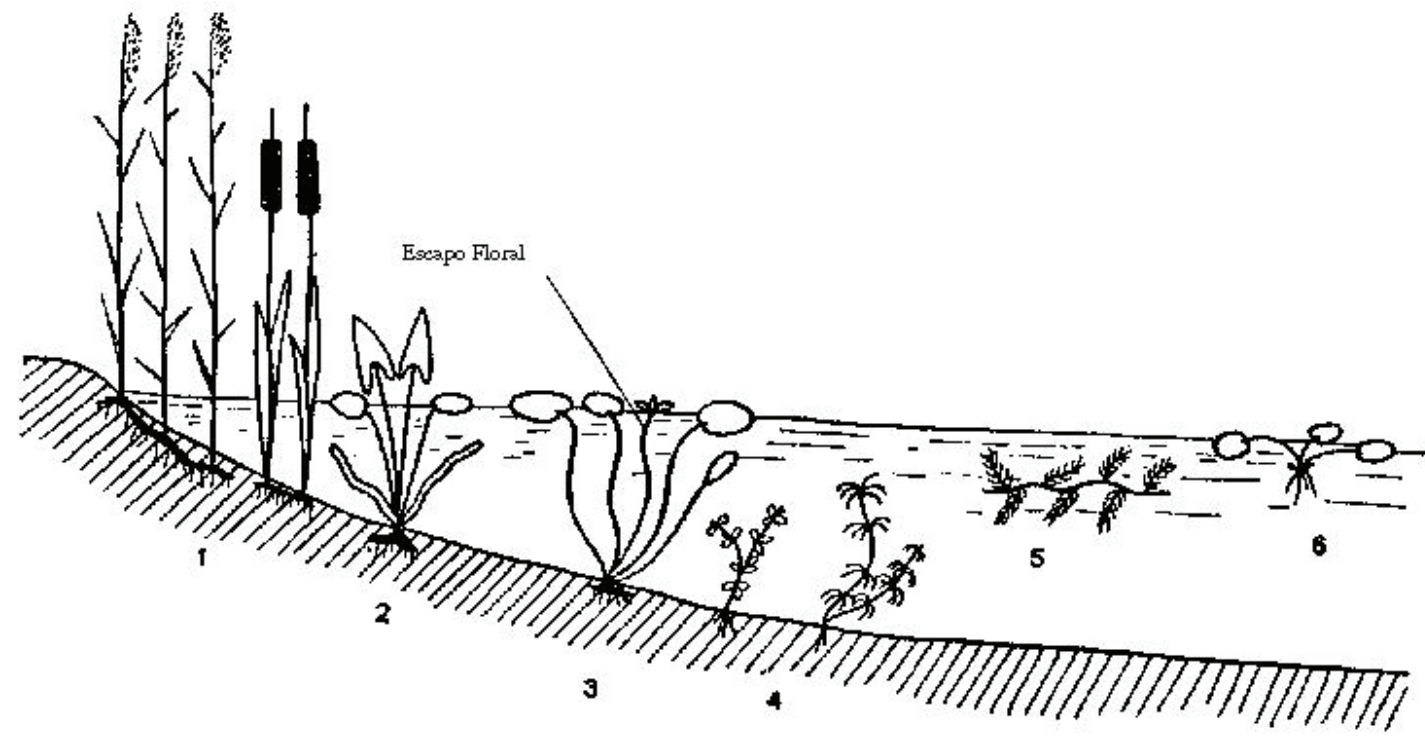

Figura 1. Formas de vida das plantas aquáticas; 1) emergentes (algumas espécies distribuídas nesta área podem ser anfíbias); 2) flutuante fixa com folhas flutuantes e emersas; 3) flutuante fixa com folhas flutuantes; 4) submersa fixa; 5) submersa livre; 6) flutuante livre. As epífitas estariam sobre os órgãos de algumas destas formas (SCREMIN-DIAS, 1999, adaptado de CAMEFORT, 1977).

Figure 1. Forms of life of the aquatics plants; 1) emergent (some species distributed in this surface can be amphibious); 2) floating fixed with floating leaves and emergents; 3) floating fixed with floating leaves; 4) submerged fixed; 5) submerged unattached; 6) floating unattached. The epiphytes would be on the some of these forms (SCREMIN-DIAS, 1999, adaptation of CAMEFORT, 1977)

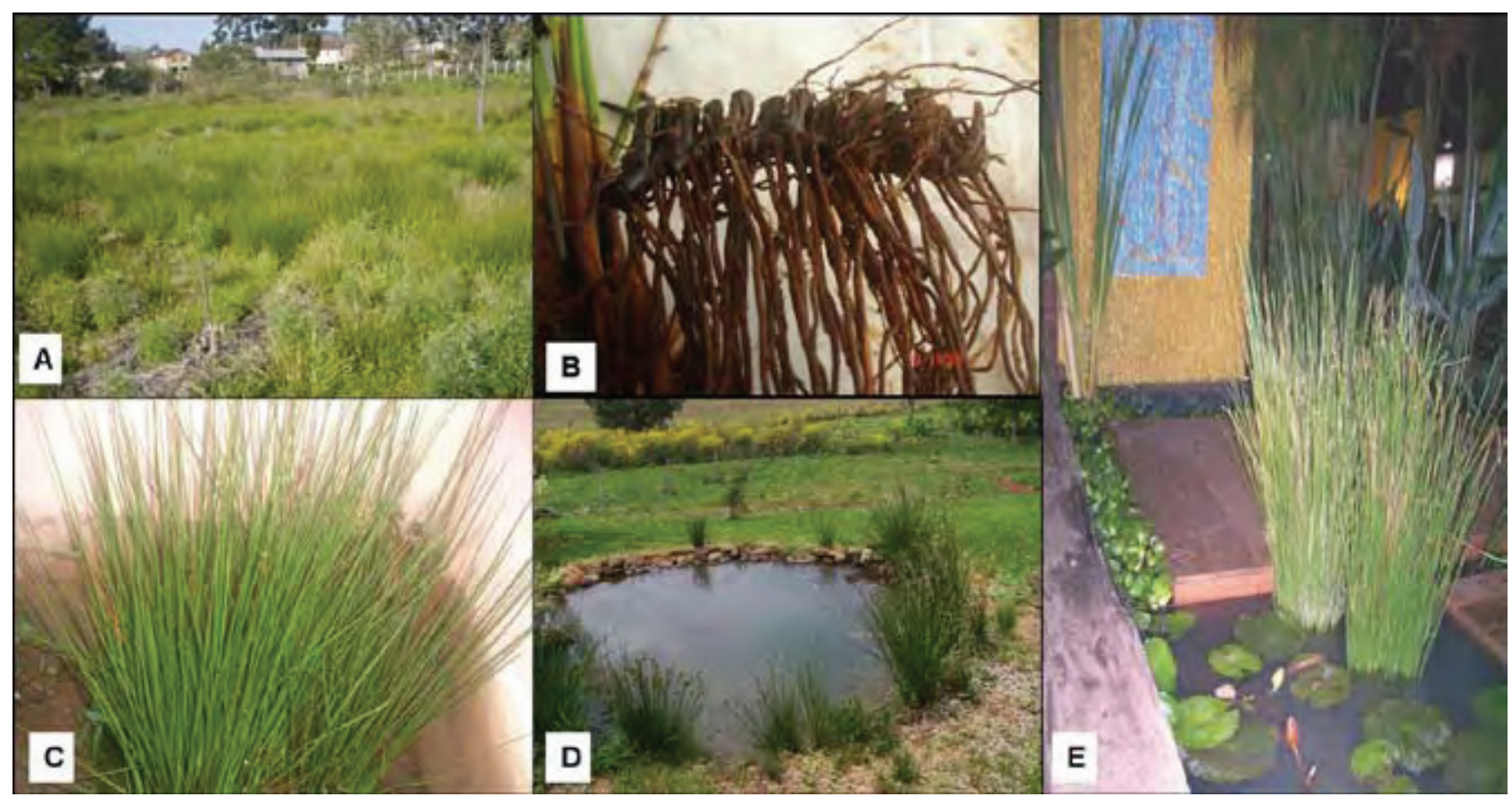

Figura 2. A) Juncal em Erechim, RS; B) Aspecto do rizoma de Juncus effusus L.; C) Touceira de junco em que é possível observar os diversos planos verticais das hastes (UPF, Passo Fundo, RS, 2006); D) Junco utilizado em paisagismo na mostra da Fiaflora 2005 em São Paulo; E) Junco utilizado em paisagismo em jardim rural da rota turística "Caminho das topiarias", em Victor Graeff, RS (2006) (fotos das autoras)

Figure 2. A) Juncus in Erechim, RS; B) Aspect of rhizom of Juncus effusus L.; C) Crowns of Juncus with diverse vertical plans of stems (UPF, Passo Fundo, RS, 2006); D) Juncus used in landscape in the exposition Fiaflora 2005 in São Paulo; E) Juncus used in landscape in rural garden of the touristical route "Caminho das topiarias", in Victor Graeff, $R S$ (2006) (authoresses'photographs) 